\title{
Healthcare information and the rural primary care doctor
}

'People are dying for lack of healthcare knowledge.' (Pascal Mouhouelo at the launch of HIFA2015, Mombasa, Kenya, 2006)

'I do not need to know everything. I just need to know where to find it when I need it.' (Albert Einstein)

Health inequity and improper dispensing of social justice is a huge topic of which one aspect is healthcare information and access to it. Access to health information is a 'prerequisite for meeting the Millennium Development Goals,' ${ }^{1}$ and lack of knowledge and information, especially in resource-poor settings, impedes the delivery of quality healthcare and contributes to many preventable deaths worldwide. Three out of four doctors responsible for care of children in district hospitals in seven less developed countries reported inadequate knowledge in managing common childhood illnesses such as childhood pneumonia, severe malnutrition and sepsis. ${ }^{2}$ A review ${ }^{3}$ concluded that information deficiency exists 'right across the health workforce' and can be associated with provision of suboptimal care.

In the Internet era information is widespread and readily available. However, problems are evident when considering the information needs of primary care physicians in rural environments in developing countries. Topping the list is lack of access to relevant information, which retards 'knowledge-based healthcare' in developing countries. ${ }^{4}$

Internet and online information sources have improved access and removed physical barriers to information flow. Paid access limits the availability of knowledge in low-income countries, but while this has prompted the development of initiatives such as openaccess publications and the HINARI Access to Research in Health Programme set up by the World Health Organization, demanding universal access to the Internet seems like a sin in countries where much of the remote countryside does not have electricity, sanitation and potable, safe water. However, there are ways around this problem. Wireless technologies and mobile-based information dissemination have been successful in some developing countries, including India. ${ }^{5-8}$ Although results are encouraging, their long-term operational efficacy and feasibility remain unproven.

The issue of implementation comes next. Chanakya (an Indian philosopher of a bygone era) said that knowledge vested within books, and money held safe in another man's hands, are of no use to one when the need for them arises. Information that has been accessed but not implemented does not benefit the community. Access alone also does not guarantee proper utilisation. ${ }^{9}$ Most health professionals in low- and middle-income countries have had no training in searching and locating the most relevant and high-quality studies. Even if they have access to large databases, their literature searching ability is poor. A typical problem is refining information obtained to apply to the rural setting. Of barriers to overcome, the most obvious is limitations of the rural practice infrastructure. First-World information may be contextually inappropriate when resources are very limited. For example, management of acute coronary syndromes in the rural setting represents a difficult balance, when the practitioner has nothing but the clinical eye and an ECG strip to aid diagnosis, and there is no access to thrombolytic therapy or surgical interventions. Implementation of accessed information also requires training of healthcare workers in critical appraisal of available evidence in the local context
Often healthcare in remote areas depends on mid-level providers who are not as comprehensively trained as doctors. Although their main responsibilities are defined and they have basic training in management and diagnosis, misbeliefs and lack of knowledge are common. ${ }^{10,11}$ Diarrhoea is an example of the dangers of inadequate and improper information. The emergency rooms of rural hospitals in developing countries see many patients with diarrhoea, advanced dehydration and malnutrition, demanding immediate therapy. Many of these patients have been 'counselled' by misinformed advisors (including family elders or traditional healers) to not take foods and fluids while the diarrhoea lasts, resulting in life-endangering dehydration. In infants and neonates the outcome may be fatal. Looking at breastfeeding, wrong information can prove harmful both in the short and long term. Studies ${ }^{12,13}$ from India found that knowledge regarding proper breastfeeding practices was lacking among medical and nursing personnel. Currently health workers are trained to support mothers in proper breastfeeding practices under initiatives such as the Baby Friendly Hospital Initiative (BFHI).

Lack of information appropriate for the epidemiological profile of a specific area is no less important. The need for populationspecific evidence cannot be over-emphasised, as disease patterns and trends vary throughout the globe and treatment that is effective in one environment might not be in another. Data on local patterns of diseases urgently need to be collected and communicated to healthcare personnel, to aid in their delivery of care. Although medical students in the era of evidence-based medicine are taught to shun anecdotal evidence, in the absence of relevant high-level data such as a systematic review or randomised controlled trial we may consider looking into local records and deciding what constitutes evidence in that niche. ${ }^{14}$ However, this requires proper maintenance of patient records, preferably in an electronic format, which is difficult to achieve in resource-poor areas.

Collaborative platforms through online discussion groups potentially form interesting ways to globally share and learn from experiences of local problem solving. Campaigns such as HIFA2015 (Healthcare Information For All by 2015), ${ }^{15}$ which aim to maximise access to and utilisation of information for provision of quality healthcare, are supported by leading organisations and institutions. The goal of HIFA2015 is 'By 2015, every person worldwide will have access to an informed healthcare provider'. Importantly, HIFA2015 defines healthcare providers as including mothers, family caregivers and other ordinary people as well as health workers, as their decisions in first aid or the early stages of illness often mean the difference between life and death.

In conclusion, there is a chronic and severe lack of healthcare information in the primary care setting, with no imminent solution. Without a structured and efficient referral system, and proper healthcare information and infrastructure at the rural level, merely increasing the number of healthcare workers or healthcare advice dispensers will be a temporary solution. Funding to maintain and sustain doctors' training and retraining to suit rural needs, and enabling them to access and implement the best possible informed healthcare, represents the only long-lasting solution. Universal access to information is difficult to achieve, but not impossible with international multisectoral collaboration involving all stakeholders. We encourage all readers and publishers, information professionals, policymakers and health professionals to join us on this global campaign of HIFA2015 at the discussion forum at www.hifa2015.org. 
Acknowledgements. We thank Dr Neil Pakenham Walsh, co-ordinator of the HIFA 2015 programme, for his suggestions while preparing the manuscript and acknowledge the positive impact of the HIFA2015 forum in formulating this article.

Conflicts of interest. The authors have no financial conflicts of interest. However, PC and TB are country representatives at HIFA2015. VS is the Chief Executive Officer of QMed Knowledge Foundation, which provides training and information support to healthcare professionals and students.

\section{Pranab Chatterjee \\ Independent researcher \\ Kolkata \\ India}

\section{Tamoghna Biswas}

Adrija Datta

MB BS students, Medical College Kolkata

\section{Vasumathi Sriganesh}

QMed Knowledge Foundation

India

Corresponding author: P Chatterjee (mail@pranab.in)

\section{References}

1. Pakenham Walsh N. Healthcare Information For All by 2015. Updated December 2008. http://www. ehealth-connection.org/wiki/images/d/d8/HIFA2015_Presentation.pdf (accessed 7 November 2011).

2. Nolan T, Angos P, Cunha AJ, et al. Quality of hospital care for seriously ill children in less-developed countries. Lancet 2001;357:106-110. http://www.thelancet.com/journals/lancet/article/PIIS01406736(00)03542-X/fulltext

3. Pakenham-Walsh N, Bukachi F. Information needs of health care workers in developing countries: literature review with a focus on Africa. Human Resources for Health 2009;7:30. http://www.humanresources-health.com/content/7/1/30

4. Godlee F, Pakenham-Walsh N, Ncayivan D, Cohen B, Packer A. Can we achieve health information

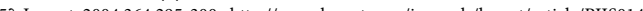
6736(04)16681-6/fulltext

5. Ramana Murthy MV. Mobile based primary health care system for rural India. http://www. w3.org/2008/02/MS4D_WS/papers/cdac-mobile-healthcare-paper.pdf (accessed 7 November 2011).

. Ramachandran D, Das PD, Canny J, Cutrell E. Mobile-izing health workers in rural India. CHI '10 Proceedings of the 28th International Conference on Human Factors in Computing Systems, 10-15 April 2010, Atlanta, Georgia. http://research.microsoft.com/pubs/122814/p1889-ramachandran.pdf (accessed 7 November 2011).

7. Marcelo A, Adejumo A, Luna D. Health informatics for development: a three-pronged strategy of partnerships, standards, and mobile health. Contribution of the IMIA Working Group on Health Informatics for Development. Yearb Med Inform 2011;6:96-101.

8. Tachakra S, Wang $\mathrm{XH}$, Istepanian RS, Song YH. Mobile e-Health: The unwired evolution of telemedicine. Telemed J F Health 2003:9:247-257. http://www.liebertonline.com/doi/ abs/10.1089/153056203322502632

9. Sriganesh V. Access alone does not guarantee use: the need for training to use evidence based resources. Poster presented at the 19th Cochrane Colloquium, 19-22 October 2011, Madrid. http://colloquium. cochrane.org/abstracts/access-alone-does-not-guarantee-use-need-training-use-evidence-basedcochrane.org/abstracts/access-alone-does

10. Eriksson L, Nga NT, Målqvist M, Persson LA, Ewald U, Wallin L. Evidence-based practice in neonatal health: knowledge among primary health care staff in northern Viet Nam. Human Resources for Health 2009;7:36. http://www.human-resources-health.com/content/7/1/36

11. Broughton DE, Beigi RH, Switzer GE, Raker CA, Anderson BL. Obstetric health care workers' attitudes and beliefs regarding influenza vaccination in pregnancy. Obstet Gynecol 2009;114:981-987.

2. Taneja DK, Misra A, Mathur NB. Infant feeding - an evaluation of text and taught. Indian J Pediat 2005; $72: 127-129$.

13. Nadkarni J, Parekh P. The attitude of nurses towards breastfeeding - a cross-sectional survey. Indian Pediatrics 2000;37:572-573.

4. Frankovich J, Longhurst CA, Sutherland SM. Evidence-based medicine in the EMR era. N Engl I Med 2011;365:1758-1791

15. Smith R, Koehlmoos TP. Provision of health information for all. BMJ 2011;342:d4151. http://www.bmj. com/content/342/bmj.d4151.extract?sid=75a28a81-7825-400a-b8bf-e5cc96478e0d 